\title{
Analysis of Morphological and Molecular Genetic Diversity of Salicornia Iranica Akhani Wildlife Populations around Urmia Lake, Iran
}

Mohammad Aghaei ( $\square$ mohamadaghae@gmail.com )

Urmia University https://orcid.org/0000-0003-2951-928X

Abbas Hassani

Urmia University

Hossein Nazemiyeh

Urmia University

Babak Abdollahi Mandoulakani

Urmia University

Mohammad Saadatian

Soran University

\section{Research Article}

Keywords: Plant Breeding, Geographical distance, Cluster analysis, ISSR, Gene analysis

Posted Date: June 11th, 2021

DOI: https://doi.org/10.21203/rs.3.rs-584493/v1

License: (c) (1) This work is licensed under a Creative Commons Attribution 4.0 International License. Read Full License 


\section{Abstract}

Salicornia is a halophyte plant capable of being irrigated with seawater, which can be used as an alternative food. Given this, it is necessary to study the potentials of this plant's morphological diversity in the natural environment. In this study, 33 wild populations of Salicornia were collected from different geographical areas around Urmia Lake during the flowering stage, and some morphological traits and 25 ISSR loci of the plant were measured. Based on morphological traits and the cluster analysis, Salicornia populations were divided into four groups. Overall, the high percentage of polymorphic gene loci (65.69\%), the average number of effective alleles per gene locus (1.63), and the Shannon data index (0.540) indicate that ISSR markers can be used in Identify genetic diversity to be used. Molecular data cluster analysis divided the studied populations into two main groups, which included $12.12 \%$ and $87.88 \%$ of the populations, respectively. Based on the effective analysis of the population's genetic structure and the precise classification of individuals into suitable sub-populations, the value of $\mathrm{K}=2$ was calculated. The research findings indicated that markers UBC823, B, A7, and K, and with the Shannon index, effective allele, and large heterozygosity values are markers with the highest effectiveness compared to other markers utilized, and they are used better than other compounds in genetic distance. The findings of this study will aid in parental selection studies for breeding programs of salicornia in future.

\section{Introduction}

Genetic diversity in crops and orchards is an issue long considered by plant breeders searching for new sources of germplasm to perform gene transfer, phylogenetic testing, chromosome control genes, and marker selection, among other things (Liebhard et al. 2002).

Given the role of genetic diversity in advancing breeding programs and the importance of the local population, it is necessary to study the local population's genetic diversity (Solouki et al. 2008). A variety of natural genetic resources in an area can provide beneficial genes for plant breeding. These genes have been formed and stored mainly in native plants for centuries (Naghdiabadi H.A. 2002). Many of these native species have been being introduced as new plants due to their medicinal and industrial properties (Heywood 1999). It is necessary to study genetic diversity among different species using morphological features to find desirable traits for further production (Noroozloo 2015). Morphological markers obtained from visible mutations in morphology include a wide range of genes that control morphological characteristics based on the appearance or phenotypes and serve as the first markers. They used time immemorial, that is, the location of a gene chromosome determined (Naghavi 2007). Salicornia is one of the well-known genera of the Chenopodiaceae family that grows and evolves as a herbaceous (an annual plant with juicy and fleshy stems) on the seashores and in the margins of brackish water (Isca et al. 2014). Salicornia genus consists of approximately 15 genus and 68 species (Shepherd et al. 2005). It is challenging to classify this plant species mainly due to self-pollination and diversity in local populations. 
The most treasured resources in any country include genetic resources. Plant stocks are used by breeders as a resource for genetic material for generating new varieties. For utilizing genetic resources at the highest efficiency, the stored genetic material should be known. Samples can be evaluated in accordance with the purpose of germplasm usage, including pathological, agronomic, morphological, biochemical, molecular, and histological dimensions. With the evaluation of germplasm, information about the weaknesses and strengths of the genotypes and populations and their potentials can be obtained, and genetic basis of each trait can be determined by these evaluations. Investigating genetic diversity in plants is significant from various dimensions. Generally, when genetic diversity is determined, it is beneficial for researchers for managing collections, conservation, maintenance, and specification of plants, as well as usage of plant collections (Quilot et al. 2005).

Besides the loss of leaves and morphological identification indices and the small amount of dry matter compared to wet tissue, the accurate identification of species is difficult (Ball 1964). Salicornia Iranica Akhani, an endemic species of Salicornia in Iran, grows in central Iran and is a diploid genus of Salicornia (Akhani 2008). The habitats of this plant in Iran are Fars, Semnan, Gorgan, Bushehr, Hormozgan, Yazd, Khorasan, Khuzestan, Markazi, West, and East Azerbaijan, Isfahan, Qom, and Tehran provinces (Milić et al. 2011). According to studies, species collected from seven regions surrounding Urmia lake have been identified as Salicornia Iranica (Milić et al. 2011). Salicornia species are of great importance due to their application in human therapy. In addition to the pharmaceutical industry, Salicornia is used as an additive for glass and soap (Davy et al. 2001). Salicornia, an important salinity-resistant crop, can be found in human and livestock food products (Lu et al. 2010).

The Salicornia is important as a medicinal plant, and given the fact that there are not adequate and comprehensive studies in different fields of production, The current survey was conducted in order to 1: to estimate the morphological and molecular variation among 33 wild salicornia populations, 2: to search for genetic structure of salicornia populations and identify the most effective ISSR markers, and 3: to identify the relationships between morphological characteristics and ISSR markers that could aid breeding programs. In this study, 33 populations of Salicornia grown around Urmia Lake were collected, and to evaluate the morphological and genetical variation between different populations, 55 different morphological traits were studied.

\section{Materials And Methods}

In this study, 33 wild populations of Salicornia in full bloom and plant seeds were collected from different geographical areas in the lake's vicinity (Table 1, Fig. 1). At the time of data collection, features such as the geographic area's location and characteristics (altitude and latitude) were recorded. Some populations were geographically less than a few hundred meters apart, which were considered separately based on field observations.

55 morphological traits were evaluated. 15 specimens were sampled per population, and for each plant, all 55 traits were calculated (Table 2). The morphological traits were measured in the Horticulture 
Department's plant physiology laboratory affiliated to the faculty of agriculture at Urmia University and the herbarium of the faculty of pharmacy at Tabriz University. The properties were measured using a ruler, digital caliper, scrubber, and optical microscope (Ingrouille and Pearson 1987; Kaligarič et al. 2008).

\section{Studying Genetic Diversity}

Molecular evaluation: CTAB approach (De Masi et al. 2006) was used for extraction of individual genomic DNA. Spectrophotometry and $1 \%$ agarose gel electrophoresis were performed for evaluating the quantity and quality of the extracted DNA. Using 25 ISSR primers, genotypes were recorded in the subjects. Lodhi et al. (1994) performed PCR reactions and their temperature cycle. Besides, using the GeneRuler'O Fermentas size indicator, the size of the band was determined. Genomic DNA was prepared usingthe $C T A B$ technique.

The combination of markers was used for obtaining population structure according to the data by the use of STRUCTURE software 2.3.4 (30) with 50,000 MCMC repetitions and 50,000 in-Burn time in Admixture mode in varying values of $K$ in a range of 1-20 (5 repetitions per $k$ ). This software was also used for estimating the membership share matrix (Q). With this matrix, it is shown that each member to what extent fits to the clusters. Using the same software, the average stabilization index (FSt) was calculated for potential subgroups. The approach proposed by Evanno et al. (2005) was used for determining the actual number of subpopulations. The basis of this approach is on $\Delta \mathrm{K}$ statistic breaking a function's slope when there is the maximum probability for a hypothetical number.

\section{Statistical Analysis Of Data}

The ANOVA and variation within-group expressed as coefficient of variation for quantitative descriptors calculated for each group and the whole collection. Mantel test, and principal components analysis (PCA) performed using XLSTAT 2018.1 statistical software. The first and second principal component axes scores were plotted to aid visualization of origin group differences and detect morphological variation in the collection.

Analysis of Data: population structure was studied using bands from all marker matrices. Using different algorithms, such as UPGMA, Single linkage, and Complete linkage, cluster analysis was performed. These algorithms were employed as zero (absence) and one (presence) scoring. The clusters were drawn in the present work using Mega software. Also other data were analyzed using the following software: NTSys version 2.0.1.5, SAS 9.2, SPSS, GenAlex, Mega, Excel, and PopGene.

\section{Results}

The variation and the mean traits were examined for different populations. Among the studied populations of Salicornia, the non-fertile parts on the longest secondary branch (V29) (84.75\%), the fertile 
parts on the longest secondary branch (V28) $(81.49 \% 0$ and the flowering plants in the first lateral branch (V34) (66.13\%) had the highest diversity (Table 3). According to the results, the highest and lowest number of primary lateral branches (V9) were observed in $(P 27,43)$ and $(P 22,13.4)$, respectively. Complete information about other variables is given in Table 3.

The first five of the 32 principal components (PCs), obtained have eigenvalues greater than 2. Together they accounted for about $67.28 \%$ of the total variance of Salicornia traits (Figure 3, Table 4). The first two PCs account for $42.32 \%$ of the total variability $(25.76 \%$ and $16.56 \%$, respectively) (Table 4$)$. PC1 represent ration of V7, V8, V11, V14, V16, V19, V25, V26, V31, V32, V37, V38, V39, V40, V41, V42, V44, V45, V46, V53, and V55. PC2 describe the ration of V1, V10, V13, V23, V24, V27, V30, and V43. Figure 3 and Table 4 show that traits lie around PC1 and PC2 center. The large variability of the traits allows observation such as $\mathrm{V} 10, \mathrm{~V} 31, \mathrm{~V} 39, \mathrm{~V} 41$, and $\mathrm{V} 45$, where the amount of length of longest 1 st primary branch, length of the

terminal spike, height of central floret of $3^{\text {rd }}$ fertile segment, height of side floret of $3^{\text {rd }}$ fertile segment and distance between florets on $2^{\text {nd }}$ fertile segment.

According to the results of cluster analyses by the Ward method, Salicornia populations were assigned to four groups (Figure 4). The first group contained $8.18 \%$ of populations (P16, P18, P24, P31, P20, and P22). In this group, populations with a short height, long spike, greater weight of 1000 seed, low number of Stomata, and the width across the apex on the third fertile segment were more abundant than other populations. The morphotype and inflorescences of this group was distinct from other groups. The second group covered $15.15 \%$ of the whole population (P3, P11, P23, P2, and P33), comprising populations that were within the average range of trait sizes for diverse traits. The third group hosted $15.15 \%$ of the population (P4, P6, P1, P8, and P10), and the fourth group included $51.51 \%$ of the population (P6, P30, P25, P27, P21, P26, P15, P12, P28, P28, P7, P14, P17, P5, P9, P19, P29, P13, and p32). These populations had a great height, more internodes, more lateral branches, more stomata, a great weight of 1000 seeds and the width of the third fertile segment on the terminal spike. The accurate number of groups was identified using the detection function.

\section{Genetic diversity of Salicornia populations}

We evaluated genetic diversity in 33 Salicornia populations using 42 ISSR primers. 23 primers out of 42 primers under study generated a polymorphic band design at the suitable resolution, which were employed for the subsequent analysis phases (Table 5). Totally, 204 locations (averagely 8.87 locations per primer) were produced by these primers, 134 of them were polymorphic $(65.69 \%)$. The ratio of markers to primer was 1 to 14 , averagely 5.82 (figure 5 ).

The number of effective ( $\mathrm{Ne}$ ) alleles in UBC849 was 1.25 and in PB it was 1.92 , averagely 1.63 in each gene locus. Maximum value of this statistic shows that alleles have identical frequency in this location, and this statistic's minimum shows the rarity of other alleles and one allele's high frequency in samples.

In investigating allelic diversity, the highest observed heterozygosity was found in the B marker as 0.477 , and the lowest observed heterozygosity was noticed in the UBC849 marker as 0.199 . Besides, the highest 
expected heterozygosity was observed at approximately 0.484 in B marker, and the lowest expected heterozygosity was observed at approximately 0.203 in the UBC849 marker. Examining Shannon index (I) values showed that the highest value for this index was in marker $B$ with a 0.670 and the lowest value was in UBC849 marker as 0.351 (Table 6).

The Jaccard similarity coefficient and UPGMA algorithm were used for dividing different populations into two separate groups. The first group contained $12.12 \%$ and the second group included $87.88 \%$ of the masses. Two subgroups were made in the first group, which the first one included P24, P22, P26 and P1. The second group contains the residual 29 populations (P13, P20, P18, P30, P32, P29, P19, P8, P15, P17, P5, P27, P12, P33, P28, P31, P16, P21, P23, P14, P4, P3, P2, P7, P25, P6, P10, P11, P9), which was classified into two subgroups. The first one is composed of just the $\mathrm{P} 13$ population. Also, this population was approximately different from other ones (Fig. 6).

Structure 2.3.1 software was used for analyzing genetic population structure and precise classifying individuals into proper subpopulations. As shown by a two-way diagram of optimal determination of $\mathrm{K}$ with ISSR indicator, the ISSR primer shows the best $K$ as 2, i.e., two subpopulations $(K=2)$ in the cultivars under study. The group was specified (Table 7, Table 8).

The stabilization index (Fst) is a common and appropriate measure for genetic differentiation among groups and populations. When the Fst is higher, a better allele differentiation is obtained, with a higher allele stabilization rate. Potential subgroups in $\mathrm{K}=2$ show the difference among the populations under study in two potential groups. Besides, the individuals' matrix of the share in these groups (Table 4-5) indicated belonging populations with high coefficients to one group. Barplot results demonstrated inclusion of 26 Salicornia populations in the first group (Red), and 5 populations in the second group (Green), with 2 populations had a complex structure (Fig. 7).

\section{Discussion}

The results showed that there was a significant difference between the studied populations in terms of traits in the question. Based on the mean of traits measured in the population, traits with a high percentage of variance had a wide range of trait quantities and offered a more extensive choice for traits. This difference is due to the impact of both genetic and environmental factors. Studies have shown that fluctuations in soil and water salinity lead to physiological and phenotypic changes in the plant. Also, high plant density in a population restricts the number of branches and glaciers formed in the plant (Kadereit et al. 2007). Self-pollination in plants, especially in diploid species, due to the flower's unique structure, leads to the formation of various local populations in Salicornia (Davy et al. 2001). The phenotypic variation coefficient between traits results in morphologically different plants manifests distinct genetic variations in different regions (Rezapour 2018). Together with the weight of 1000 seeds, these traits undermine the plants' ability to produce satisfying seeds. With an increase in the number of internodes and lateral branches, the weight of 1000 seeds drops. Most of the plant energy comes spent on vegetative growth. Studies have focused on Salicornia's two species in Iran (S. Biglovi, and S. Persica). 
In S. Biglawi species, raising the salinity of irrigation water to $45 \mathrm{ds} / \mathrm{m}$ reduces the height and dry weight of the plant. In Persica species, increasing the irrigation water salinity had no effect on plant height but significantly decreased the dry weight (Rezapour 2018).

The cluster analysis results showed (Fig. 4) the clustering of populations is incompatible with geographical distribution. It may be due to sources of seed diversity caused by migration to different areas. Therefore, it may not be limited to different geographical regions in selecting parents for breeding projects, but it should be consistent with each population's specific capacities. By studying Salicornia Pusilla, researchers have found that the plant seeds remain attached to the inflorescence after ripening, and the spikes are trapped by a separating layer of the plant isolated in the water that may keep moving with the flow of water up to three months. They may even germinate but do not grow until the seeds are deposited in sediments (Dalby 1962). This feature may explain the common seed origin in the studied populations. Using 22 growth parameters, the researchers evaluated 11 Salicornia Bigelovii populations in the field and divided the cluster analysis of studied populations into four groups (Lyra et al. 2016). Contrary to our study, the results of research on the genetic diversity of six Salicornia Ramosissima populations in central Germany showed that it is consistent with geographical distribution (Krüger et al. 2002). A review of the genetic diversity of the two species of saline Salsola manifested a significant difference in this plant and the environmental conditions of the plant, suggesting that disparity in salinity, nutrition, $\mathrm{pH}$, and soil moisture changes the vegetative type of plants (Shuyskaya et al. 2017). The results of analyzing the main components confirmed the clustering obtained from the cluster decomposition. The analysis of main components sheds light on the difference between individuals and allowing the identification of groups and the relationship between individuals and variables (Martínez-Calvo et al. 2008). Based on the results of this analysis and multivariate analysis, four Salicornia populations were divided into three separate groups: the first component (46.11\%), the second component $(41.35 \%)$, and the overall component (87.46\%) of the entire diversity. The study of the morphological diversity patterns of 52 Salicornia populations in 31 regions of Northern Europe using 28 morphological traits demonstrated diversity in the studied populations. The main components' analysis revealed the first five components accounted for $79.8 \%$ of the total diversity. In the first component, characteristic spikes included the length of fertile segment and length of the spike (explaining $40 \%$ of the diversity, and in the second component, they included the size of the plant and the branches (explaining $18.1 \%$ of the diversity)(Heydarian 2001). The results are aligned with our results. Principal Component Analysis revealed that V7, V8, V11, V14, V16, V19, V25, V26, V31, V32, V37, V38, V39, V40, V41, V42, V44, V45, V46, $\mathrm{V} 53$, and $\mathrm{V} 55$ contributed mostly to diversity.

Though the association between regional diversity was not that evident, a close look at the scatter plot revealed some regional adaptation level was observed. Such regional variability could be due to geographic isolation and microclimatic differences between regions. Factors such as plant population isolation, adaptation to the environment due to declining lake water levels, and strong self-pollination within the plant population may contribute to Salicornia's population diversity. The degree of morphological differentials is significantly noticeable in different populations from four groups. 
The research findings indicated that markers UBC823, B, A7, and K, and with the Shannon index, effective allele, and large heterozygosity values are markers with the highest effectiveness compared to other markers utilized, and they are used better than other compounds in genetic distance.

As stated by Dirlewanger et al. (2002), there is a relationship between the alleles number in each gene locus and the number of used markers and the samples' number. According to the findings of research on the genetic diversity of six populations of S. herbacea in South Korea, where 6 ISSR markers were used, 39 polymorphic bands were obtained out of 49 bands, with an average of the effective allele for each gene locus as 1.22. The mean genetic index was 0.249 and the mean Shannon index was 0.382 . These researchers mentioned that for achieving high diversity in populations Salicornia, a wider research scope is required to be chosen (Kim et al. 2017).

These populations were separately gathered because of varying morphological types compared to other populations. Also, this difference is shown in the results. The second subgroup included P26 and P1 populations, with different appearances compared to other populations. They had a height higher than average, particularly the highest height was observed in P26 population among all populations. Moreover, long glazes were observed in these two populations. Additionally, it shows all botanical properties of $S$. Iranica (Akhani 2008).

In earlier Iranian research works on Salicornia, 36 samples of Salicornia were collected by (Heydarian 2001)from different saline areas. He specified this plant's genetic diversity by the use of 17 RAPD molecular markers, Jaccard similarity coefficient, and UPGMA approach. The subjects were categorized into 7 classes. Moreover, 18 Salicornia populations were evaluated by (Mohammadi 2012)that were collected from different regions in Iran. He used AFLP markers and categorized the individuals into 4 groups by the use of UPGMA method and Jaccard similarity coefficient. As shown by the research in this work, the researcher collected species from 7 regions near Lake Urmia and S. Iranica are presented, all in a group. In this research, S. Iranica species were separated from S. persica species using the AFLP marker, and they were placed in a subgroup. Additionally, the populations gathered from each area were put in a different subgroup. The genetic diversity in $11 \mathrm{~S}$. brachiata populations were evaluated in India by (Badlani 2011) by 15 ISSR and 15 RAPD primers. The investigated populations showed high diversity. It was also observed in both markers of the populations under study. They were grouped into 3 groups.

The resulting Barplot showed that when the membership percentage to a cluster for a genotype is higher than or equal to 0.7 , the genotype is allocated to that cluster, while if the percentage is below it, it is considered as a mixed genotype (hybrid) (Spataro et al. 2011). Generally, when the average effective allele numbers per gene locus (1.63), the polymorphic gene loci percentage (65.69\%), and the Shannon data index (0.540) are high, it is indicated that we can use ISSR markers for identifying genetic diversity.

\section{Conclusion}

This study showed that Salicornia populations growing around Urmia Lake had considerable diversity in morphological and ISSR characteristics. The incompatibility of population clustering with their 
geographical distribution may be due to different populations' exact seed origins. The populations under the genetic study were divided into two major groups by cluster analysis of molecular data, including $12.12 \%$ and $87.88 \%$. The $\mathrm{K}$ value was obtained as two according to the practical analysis of the population's genetic structure and the accurate individuals' classification to suitable sub-populations. The populations under study were classified into two groups that are because of Salicornia's self-pollination. Differences in morphological and genetic grouping may be due to the environment's effect on morphological traits. While in genetic traits, the difference between the populations was may be due to the populations' isolation due to the lowering of the lake water, and the plant was directed towards selfbreeding. Combining morphological and ISSR data may be more effective for defining genetic variation and genetic diversity within the salicornia population.

\section{Declarations}

\section{Acknowledgment}

The Urmia lake studies research institute sincerely thanks for providing part of this research's necessary funds (Grant No. 608/53).

\section{Disclosure statement}

We declare no conflict of interest.

\section{Author contributions}

M. Aghaei co-designed the research, analyzed data, and prepared figures and wrote the manuscript. A. Hassani performed the observations and measurements in the field. H. Nazemiyeh performed the observations and measurements in the field. B, Abdollahi Mandoulakani co-designed the research, performed part of the field work. M. Saadatian analyzed data, and prepared figures and wrote the manuscript.

\section{Funding}

This work was partly supported by the Urmia lake studies research institute under Grant No. (608/53)

\section{Data Access Statements}

"All data is provided in full in the results section of this paper."

"Expression all morphological and molecular data is openly available from Dryad at https://doi.org/10.5061/dryad.83bk3j9r8."

\section{References}


1. Akhani H (2008) Taxonomic revision of the genus Salicornia L. (chenopodiaceae) in Central and Southern Iran. Pak. J. Bot. 40:1635-1655

2. Badlani Ak (2011) Molecular characterization of genetic diversity in Salicornia brachiata (Roxb.) using RAPD and ISSR markers. Saurashtra University, India, Saurashtra

3. Ball PW (1964) A taxonomic review of Salicornia in Europe. Feddes Repert:1-8

4. Dalby DH (1962) Chromosome number morphology and breeding behaviour in the British Salicorniae. Watsonia 5:150-162

5. Davy AJ, Bishop GF, Costa CSB (2001) Salicornia L. (Salicornia pusilla J. Woods, S. ramosissima J. Woods, S. europaea L., S. obscura P.W. Ball \& Tutin, S. nitens P.W. Ball \& Tutin, S. fragilis P.W. Ball \& Tutin and S. dolichostachya Moss). J. Ecol. 89:681-707. doi:10.1046/j.0022-0477.2001.00607.x

6. De Masi L, Siviero P, Esposito C, Castaldo D, Siano F, Laratta B (2006) Assessment of agronomic, chemical and genetic variability in common basil (Ocimum basilicum L.). Eur. Food Res. Technol. EUR FOOD RES TECHNOL. 223 (2):273-281

7. Dirlewanger E, Cosson P, Tavaud M, Aranzana M, Poizat C, Zanetto A, Arus P, Laigret F (2002) Development of microsatellite markers in peach [Prunus persica (L.) Batsch] and their use in genetic diversity analysis in peach and sweet cherry (Prunus avium L.). Theor. Appl. Genet. 105 (1):127-138

8. Evanno G, Regnaut S, Goudet J (2005) Detecting the number of clusters of individuals using the software STRUCTURE: a simulation study. Mol. Ecol. 14 (8):2611-2620

9. Heydarian Z (2001) Collection and determination of genetic diversity of Salicornia plant based on Rapid molecular marker., Shiraz University, Shiraz

10. Heywood V (1999) Trends in agricultural biodiversity. Perspectives on new crops and new uses, J. Janick edn. ASHS Press, Alexandria, VA

11. Ingrouille M, Pearson J (1987) The pattern of morphological variation in the Salicornia europaea L. aggregate (Chenopodiaceae). Watsonia 16:269-281

12. Isca VMS, Seca AML, Pinto DCGA, Silva AMS (2014) An Overview of Salicornia Genus: The Phytochemical and Pharmacological Profile. Natural Products: Res Rev. Vol. 2, vol 2.

13. Kadereit G, Ball P, Beer S, Mucina L, Sokoloff D, Teege P, Yaprak AE, Freitag H (2007) A taxonomic nightmare comes true: phylogeny and biogeography of glassworts ( Salicornia L., Chenopodiaceae). TAXON 56:1143-1170. doi:10.2307/25065909

14. Kaligarič M, Bohanec B, Simonovik B, Šajna N (2008) Genetic and morphologic variability of annual glassworts (Salicornia L.) from the Gulf of Trieste (Northern Adriatic). Aquat. Bot. 89:275-282. doi:10.1016/j.aquabot.2008.02.003

15. Kim S-K, Cho YS, Hur YB, Song JH, Jeong HD, Chung SO (2017) Genetic Diversity of Salicornia herbacea according to Habitat Area by ISSR Markers. Korean J. Environ. Ecol. 31 (6):492-499

16. Krüger AM, Hellwig FH, Oberprieler C (2002) Genetic diversity in natural and anthropogenic inland populations of salt-tolerant plants: Random amplified polymorphic DNA analyses of Aster tripolium 
L. (Compositae) and Salicornia ramosissima Woods (Chenopodiaceae). Mol. Ecol. 11:1647-1655. doi:10.1046/j.1365-294X.2002.01562.x

17. Liebhard R, Gianfranceschi L, Koller B, Ryder CD, Tarchini R, Van De Weg E, Gessler C (2002) Development and characterisation of 140 new microsatellites in apple (Malus $\mathrm{x}$ domestica Borkh.). Mol. Breed. 10:217-241. doi:10.1023/A:1020525906332

18. Lodhi MA, Ye G-N, Weeden NF, Reisch BI (1994) A simple and efficient method for DNA extraction from grapevine cultivars andVitis species. Plant Mol. Biol. Rep. 12 (1):6-13

19. Lu D, Zhang M, Wang S, Cai J, Zhou X, Zhu C (2010) Nutritional characterization and changes in quality of Salicornia bigelovii Torr. during storage. LWT - Food Sci. Technol. 43:519-524. doi:10.1016/j.Iwt.2009.09.021

20. Lyra DA, Ismail S, Butt KURB, Jed Brown J (2016) Evaluating the growth performance of eleven Salicornia bigelovii populations under full strength seawater irrigation using multivariate analyses. Aust J Crop Sci. 10:1429-1441. doi:10.21475/ajcs.2016.10.10.p7258

21. Martínez-Calvo J, Gisbert AD, Alamar MC, Hernandorena R, Romero C, Llácer G, Badenes ML (2008) Study of a germplasm collection of loquat (Eriobotrya japonica Lindl.) by multivariate analysis. Genet. Resour. Crop Evol. 55:695-703. doi:10.1007/s10722-007-9276-8

22. Milić D, Luković J, Dan M, Zorić L, Obreht D, Veselić S, Anačkov G, Petanidou T (2011) Identification of salicornia population: Anatomical characterization and RAPD fingerprinting. Arch. Biol. Sci. 63:1087-1098. doi:10.2298/ABS1104087M

23. Mohammadi A (2012) Collection and determination of genetic diversity of Salicornia plant using markers AFLP. Shiraz University, Shiraz

24. Naghavi MR, Ghareyazie, B. and Hossenei Salekdeh, GH (2007) Molcular marker.340

25. Naghdiabadi H.A. YD, Nazari F., and Sajed M.A. (2002) Yield Seasonal changes and the composition of the thyme essential oil (Thymus vulgaris L.) At different planting densities. Medicinal plants 2:5156

26. Noroozloo YA, Mirjalili, M. H., Nazeri, V. , Araghi, A. R. M. (2015) Evaluation of some ecological factors, morphological traits and essential oil productivity of Stachys lavandulifolia Vahl. in four provinces of Iran. Iranian Journal of Medicinal and Aromatic Plants 30:985-997

27. Quilot B, Kervella J, Génard M, Lescourret $F$ (2005) Analysing the genetic control of peach fruit quality through an ecophysiological model combined with a QTL approach. J. Exp. Bot. 56 (422):3083-3092

28. Rezapour M, Fattahi, M. (2018) Evaluation of diversity in some morphological characteristics and essential oil antioxidant activity among of wild-growing populations of Golpar Heracleum persicum Desf. ex Fischer冈 from Northwest of Iran. vol 6. Eco-phytochemical Journal of Medicinal Plants.

29. Shepherd KA, Macfarlane TD, Colmer TD (2005) Morphology, anatomy and histochemistry of salicornioideae (chenopodiaceae) fruits and seeds. Ann. Bot. 95:917-933. doi:10.1093/aob/mci101

30. Shuyskaya E, Toderich K, Gismatullina L, Rajabov T, Khohlov S (2017) Genetic diversity of two annual Salsola species (Chenopodiaceae) among habitat types in desert plant communities. 
Biologia (Poland) 72:267-276. doi:10.1515/biolog-2017-0032

31. Solouki M, Mehdikhani $H$, Zeinali $H$, Emamjomeh AA (2008) Study of genetic diversity in Chamomile (Matricaria chamomilla) based on morphological traits and molecular markers. Sci. Hortic. 117:281287. doi:10.1016/j.scienta.2008.03.029

32. Spataro G, Tiranti B, Arcaleni P, Bellucci E, Attene G, Papa R, Zeuli PS, Negri V (2011) Genetic diversity and structure of a worldwide collection of Phaseolus coccineus L. Theor. Appl. Genet. 122 (7):12811291

\section{Tables}

Due to technical limitations, tables are only available as a download in the Supplemental Files section.

\section{Figures}




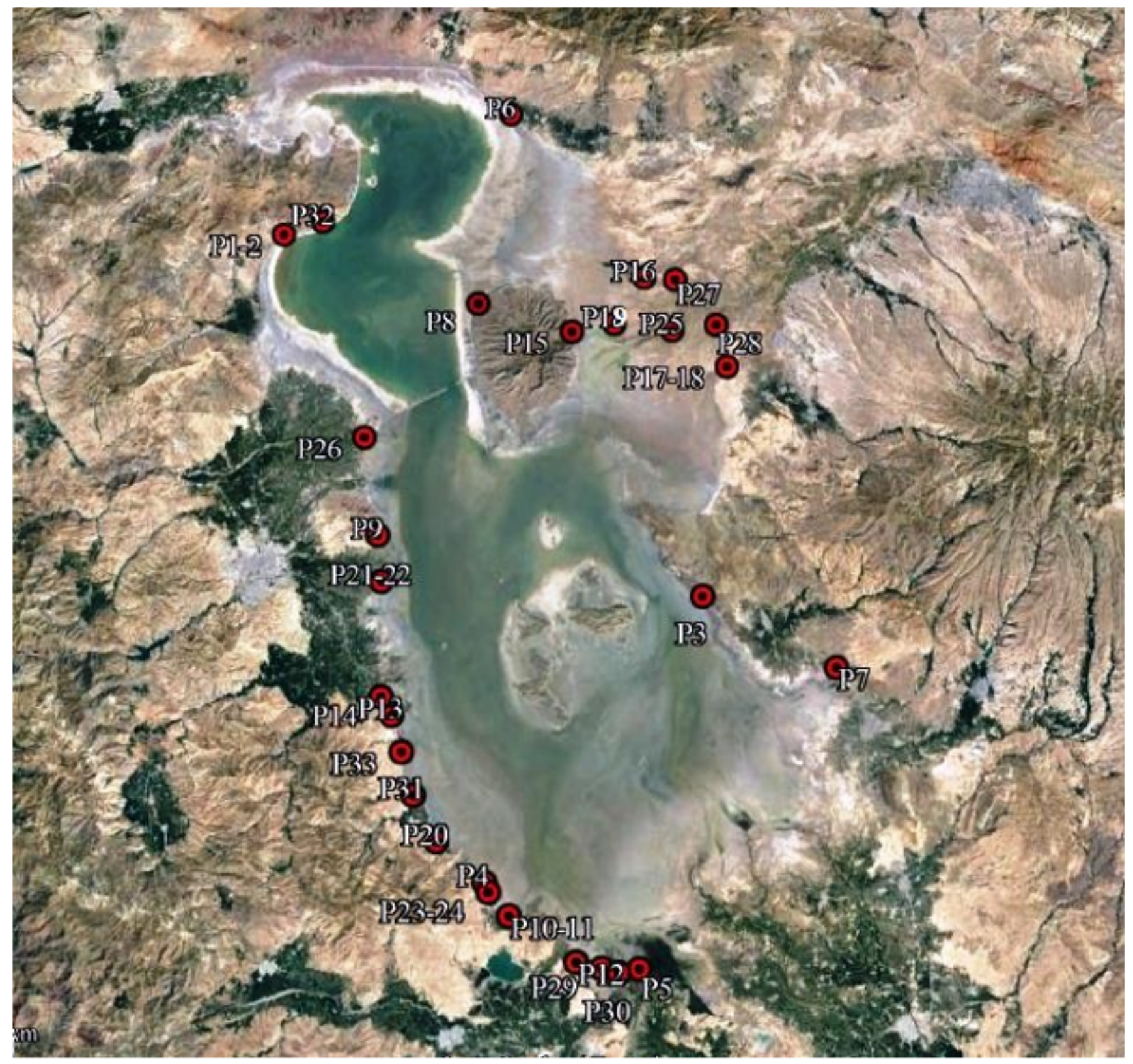

\section{Figure 1}

Sampling regions of different Salicornia populations around Urmia Lake. Map constructed with Google Maps. Note: The designations employed and the presentation of the material on this map do not imply the expression of any opinion whatsoever on the part of Research Square concerning the legal status of any country, territory, city or area or of its authorities, or concerning the delimitation of its frontiers or boundaries. This map has been provided by the authors. 


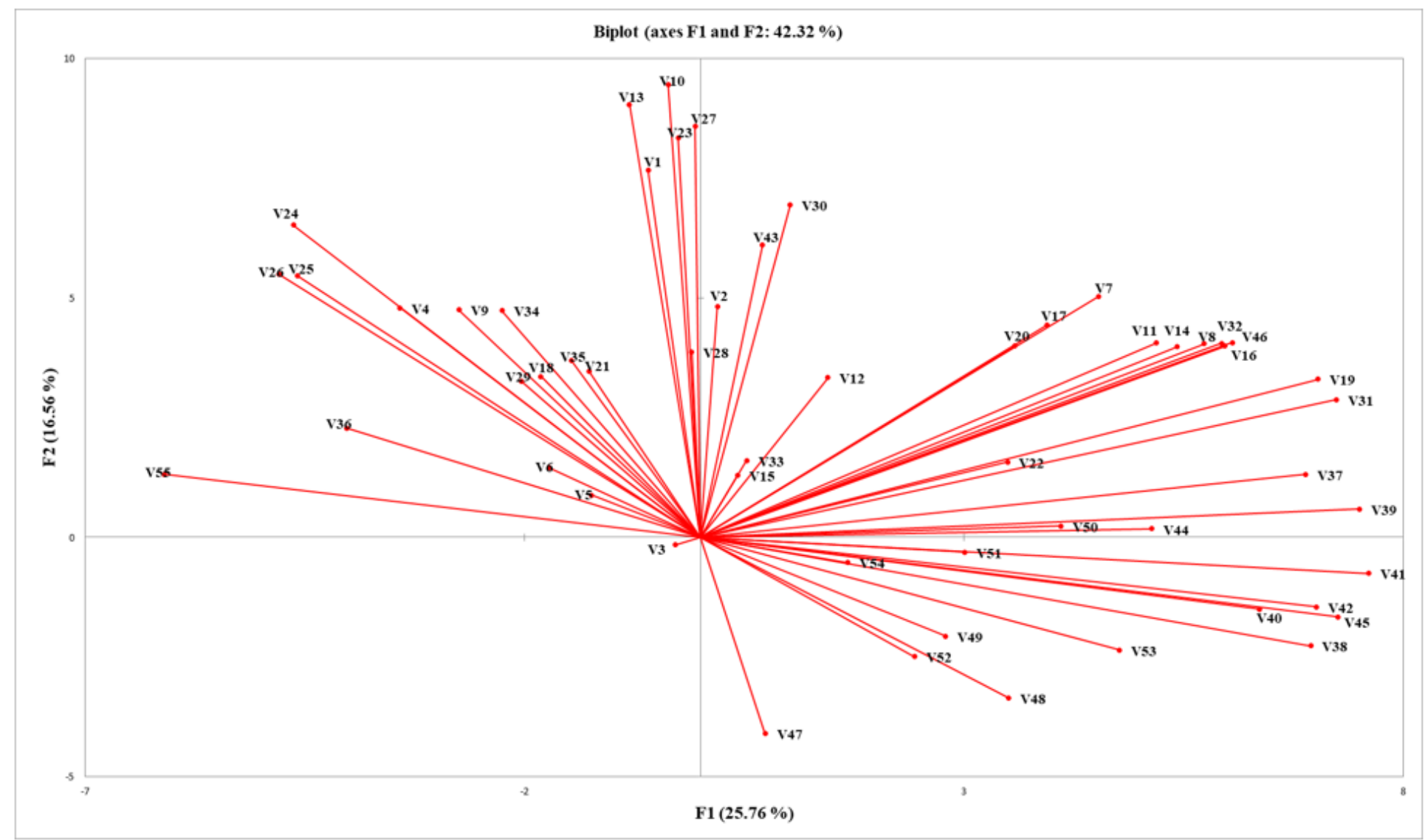

Figure 2

Plots of variables in 33 salicornia populations for the first two PCA 


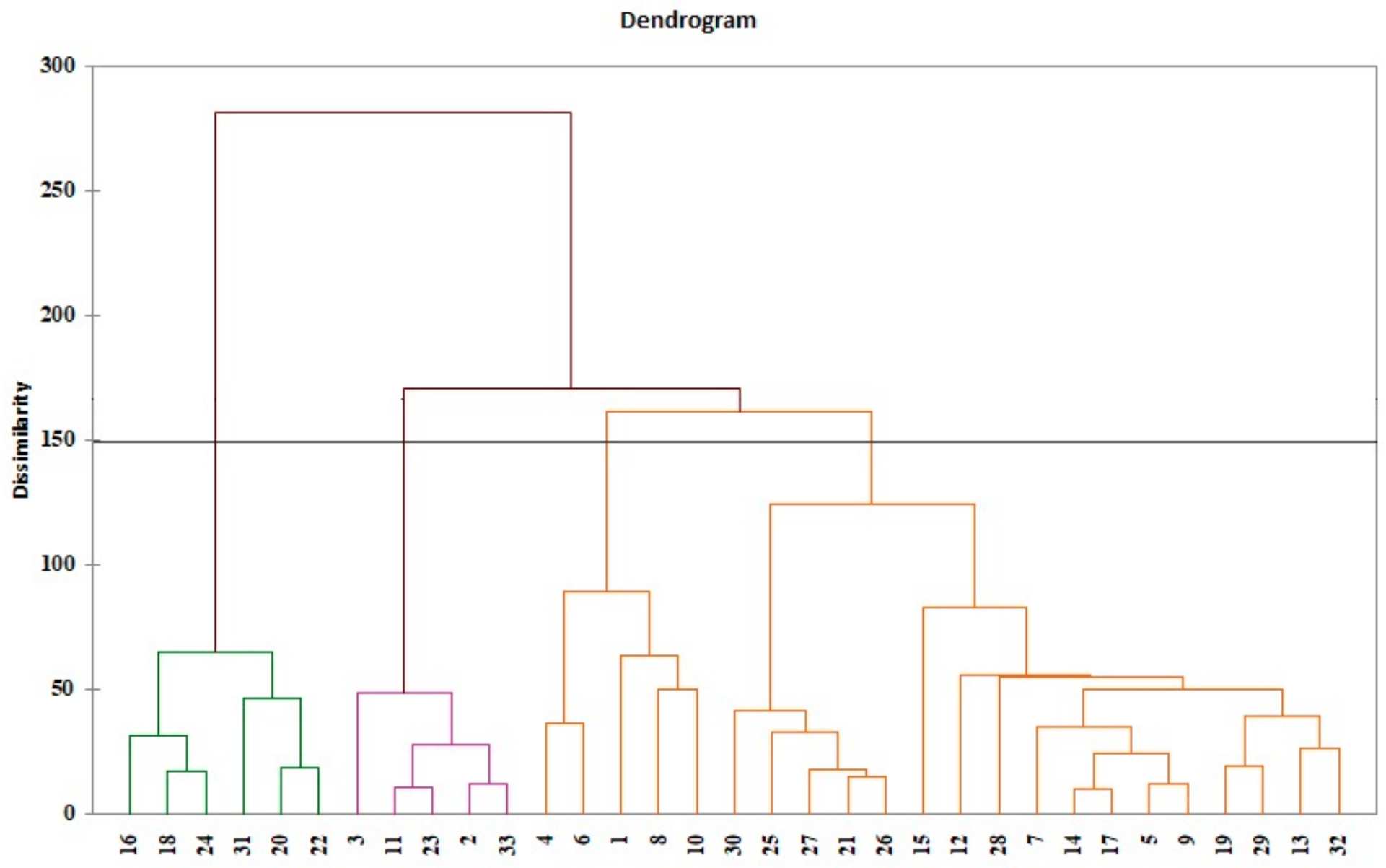

Figure 3

Cluster analysis of different Salicornia populations based on morphologic traits 


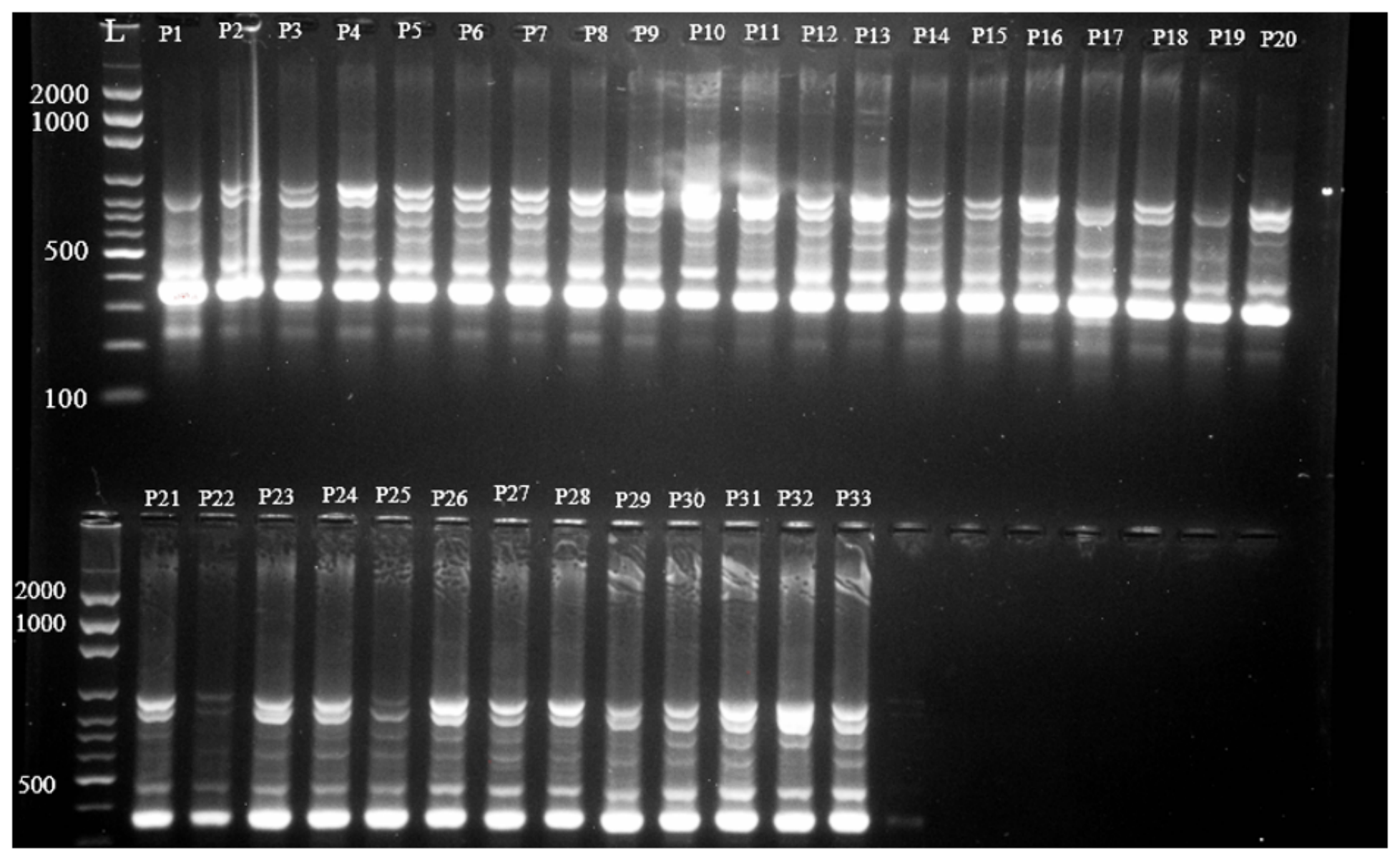

\section{Figure 4}

Fingerprint images of Salicornia populations with A13 primer UBC860 


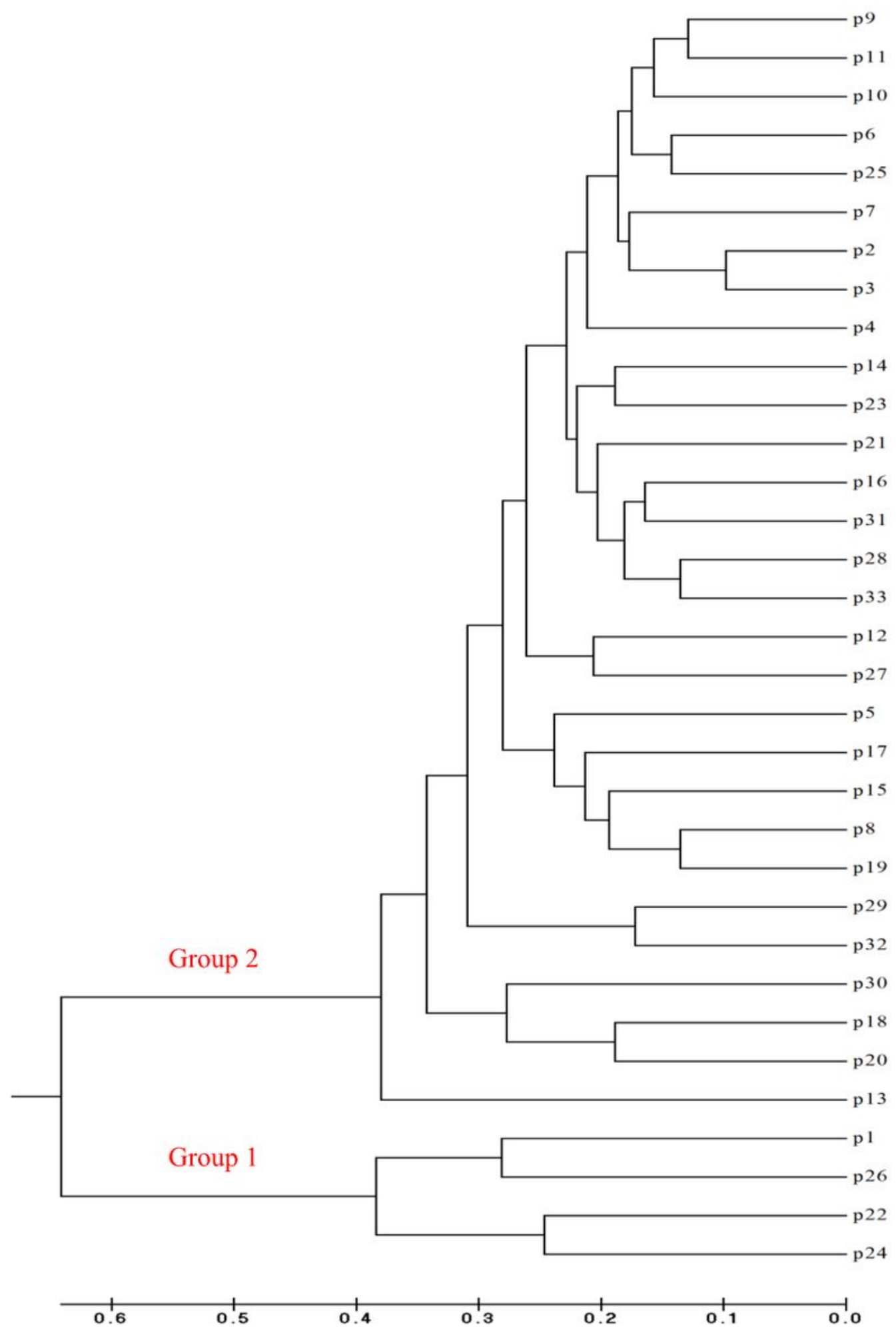

Figure 5

Cluster analysis of Salicornia populations based on algorithm UPGM 


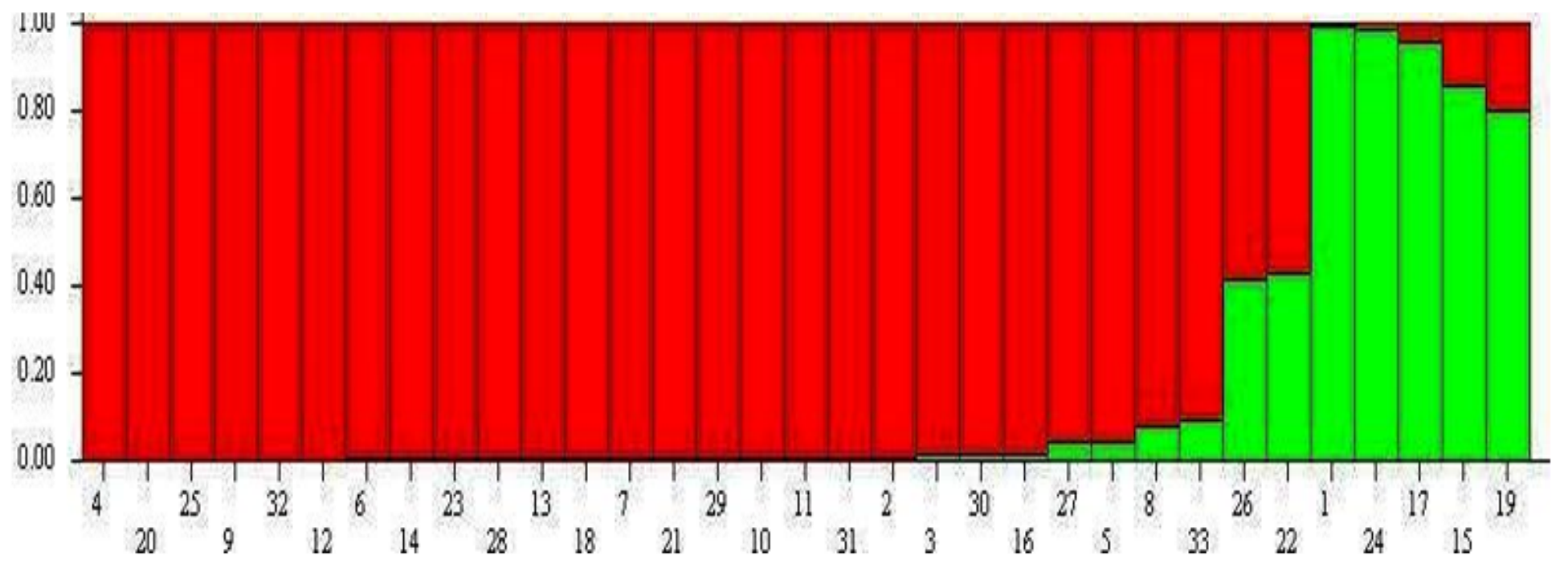

Figure 6

Cluster analysis based on Bayesian model 33 Salicornia population studied based on ISSR marker (K = 2). Each color represents a subset or cluster. The vertical axis shows the coefficient of belonging of each person to each cluster

\section{Supplementary Files}

This is a list of supplementary files associated with this preprint. Click to download.

- Table.docx 